without molesting those people with whom he is brought into contact. Recovery is said to have been effected in a few cases of fairly recent origin by a method which somewhat resembles psycho. analysis, but differs from it in that the physician seeks, in the first instance, to obtain a positive transference before tackling the disease itself. He gets the patient to give a complete history of his life, endeavouring meanwhile to discover incidents and characteristics which have a bearing on his delusional state, and to disclose them. During the whole of this process, which takes 20 to 30 hours, he accepts the patient's point of view throughout until he ultimately gains his whole confidence and convinces him of his friendship, without, however, actually encouraging his delusions or agreeing with every word he says. Then, when a suitable opportunity offers, he suggests that the patient may have come to an erroneous conclusion about some quite insignificant occurrence. After a few more sittings, as opportunity offers, he points out another minor occasion when the patient might have been mistaken. So he goes on until he sees his chance for tackling the main delusion and pointing out that eren here he may have also been mistaken. The physician takes advantage of any attitude of doubt and completes the cure by "therapeutic conversation." The whole procedure requires an enormous amount of tact, patience, and skill. Moreover, the physician must be familiar with these mechanisms of paranoia which have been discovered by the psycho-analytic method.

Concluding Remarks.

The main object of these lectures has been to expound the principles of psycho-analysis proper, its technique, the psychological mechanisms which it has disclosed, and the bearing of these mechanisms, not only on many of the patients in the asylums of Great Britain, but also on an enormous number of people pursuing their ordinary vocations in spite of curable mental worries or spending an enormous proportion of their time and income in nursing homes. The physician who will undertake the radical cure of these poor sufferers will earn the gratitude of society as well as that of the patients, which is always unbounded; but he must be a man of courage, for he will have to face the opposition of the " herd" for many years to come. In spite of all we may say, the subject of sex will remain taboo, yet no physician of experience can deny the enormous rôle played by sexual conflicts in the genesis of the neuroses. I do think that cases sometimes occur in which the psychogenetic conflict is non-sexual, but they are so rare that I can see the psycho-analytic literature of the future augmented by reports of such cases as curiosities.

Although I attach so much importance to psychoanalysis, I hope that no words of mine will detract from the systematic investigation of cases by other methods. It would be deplorable, for instance, if attention to psychological investigation should detract from the work of the clinical laboratory and thus allow a positive Wassermann reaction, so common in dementia præcox, for example, to be overlooked.

It has often been said that the frequency of mental disease is due to the effect of civilisation, to the hurry, bustle, and struggle for existence associated with urban life, to defective sanitation, insufficient sleep, overwork, poverty, brain-fag, education, and a host of other things incident on civilisation. With all our modern corve siences, the Poor-law, hygienic surroundings, hospitals, comfortable railways with restaurant cars and sleeping accommodation, typewriters and telephones, such a view is manifestly erroneous.

That insanity is the result of civilisation is obvious to anybody who looks the facts in the face: but psycho-analysis has revealed that the essential factor is not hurry, bustle, and brain-fag, but the repression of the instincts enforced by civilisation.

It is not to be supposed that the prophylaxis of insanity lies in letting loose the reins of licentiousness and depravity. The problem is far mone intricate than this, and it is not likely that it will be solved in the present century, much less in our own time. The mystery at present surrounding sex and birth problems must be removed by systematic education of the young in such matters, early marriage must be made more possible than exist. ing circumstances will permit, and old men and parents will have to remember the days of their own youth when they enact the laws which are to govern society. Moreover, the whole populace will have to be educated in such matters before any serious change can be accomplished.

\section{CEREBRO-SPINAL MENINGITIS. WITH NOTES ON TWO EPIDEMICS.}

BY E. NORMAN BUTLER, B.A. CANTAB., M.R.C.S. ENG., L.R.C.P. LOND.

MEDICAL OFFICER, MAGADI RAIITAY, BRTTISH EAST AFRICA; LATE HOUSE PHYSICIAN, CASUALTY OFFICER, AND RFSIDENT AY THETIS $R$, ST. THOMAS'S HOSPITAL : LATE CAPTAIN, EAST AFRICAN MEDICAL SERYICE.

Cerebro-spinal meningitis, or spotted fever, is a disease of great importance to the practitioner, forthough nowadays large epidemics are rare in. England, the occurrence of the disease in small numbers is frequent in our larger towns. In East. Africa the disease has assumed characters so virulent that it is the dread of the native and the bugbear of the employer of native labour. This is not. surprising, for in 1913 it killed, in one tribe, numbers variously estimated at 20,000 to 40,000 .

It is a curious feature of the disease that there are places in East and Central Africa where it is always endemic and seldom epidemic, as, for instance, Uganda in general and the coast town of Mombasa, whilst in the highlands of British East Africa the endemic form is not often seen, and when the disease occurs it is usually in the form of an epidemic of greater or less virulence.

In the second of the epidemics to be here described the persons involved were natives of Uganda and the borderland between British East Africa and Uganda, who were brought down to the coast to act as military porters in connexion with the campaign against German East Africa. Whilst in Mombasa three or four cases of a clearly. sporadic nature occurred, following the usual custom of that town, where amongst the natives post-basic meningitis is of continual occurrence.

\section{First Series.}

The first epidemic that came to my notice was of a much milder character than the second; it occurred at almost the same place in the highlands as the second, but amongst natives whose normal habitat more normally approximates to the altitude in which they were then living. In all, I had 8 cases in this epidemic, resulting in 4 deaths and 4 complete recoveries. Besides these a small number of cases occurred amongst natives who 
were not under my care, and these were treated by Dr. Nicholls.

I must make apology for lack of scientific methods. I have been, all through, unable to obtain a lumbar-puncture needle in this country, and lack of a bacteriological laboratory rendered microscopical examination of pus my only means of investigation of the organism.

As regards the second series of cases-the more important one-scientific observation was rendered reven less possible, by reason of the difficulties naturally encountered in such work when it is done in connexion with the transport arrangements of an expeditionary force on active service.

Case 1A.-Aged about 25. Physique poor. History of sudden onset of pain at the back of the neck and across the shoulders, and severe occipital and vertical headache. On the second day head retraction was marked, but not excessive, Kernig's sign positive ; abdominal and epigastric reflexes absent; knee-jerks normal. The plantar reflex, as with all natives, was not obtainable, owing to the thickness of the soles of the feet. On the third day there was purulent conjunctivitis in the right eye, the pus showing a Gramnegative diplococcus with an intracellular distribution. The case showed no further features of interest, and made an uneventful recovery.

CASE 2A.-Aged 20 years. Physique fair. In general the - case was almost precisely similar to the last, save that the conjunctivitis affected both eyes, the pus from which showed the diplococcus, and there was a nasal discharge of thick, yellow, creamy pus, which also contained intracellular diplococci. After four days the patient became unconscious, with very marked head retraction, and died on the eighth day. At the necropsy I found thick yellow pus in the pia-arachnoid involving the brain from base to vertex, descending into the greater fissures and all along the spinal cord.

The following is a different type of case showing more severe onset, but proceeding to complete recovery.

CASE 3A.-Aged 15. Physique poor. Onset very sudden with headache and pain at the back of the neck and across the shoulders, followed in about 12 hours by unconsciousness lasting three days, during which he was brought a seven hours' railway journey. He was fed by tube for seven days. Head retraction and Kernig's sign marked. Eventually gradual recovery commenced without any special features, and was complete in about five weeks from the onset of the disease.

The other cases of the same epidemic showed no features of special interest. The two cases that reached necropsy showed post-mortem findings similar to those in Case $2 \mathrm{~A}$.

One case that occurred in the same epidemic, in which, though the patient died before I saw him, there is very little doubt of the diagnosis, exemplifies very well another distinct type of the disease. The onset in a native of superb physique was very sudden with pains at the back of the neck and across the shoulders, and severe headache. Unconsciousness supervened in about an hour and a half, and death in six hours. At the post-mortem examination the only macroscopical feature was excess of cerebro-spinal fluid, whieh was removed from absolute clarity by the nearest possible turbidity. In none of these cases was any treatment, other than symptomatic, adopted.

I was told by my colleague, Dr. Nicholls, of the success of his prophylactic measures of burning down all the natives' huts occupied by those amongst whom his cases occurred, syringing out the nose and naso-pharynx with weak antiseptic of everyone exposed to infection, and causing them all to take a bath in a strong solution of cyllin, and immersing ali bedding, clothes, \&o., in a still stronger solution. I therefore decided to follow out the same plan of campaign, only instead of burning the huts I pulled them all down and left the coirugated iron sheets of which they were made lying under the powerful African sun for two days, and subsequently had them re-erected on a different site. The bathing of all the natives exposed to infection, together with their clothes, bedding, \&c., in cyllin 1 in 400 and $I$ in 200 respectively, was carried out, but owing to there being considerably over 500 natives to be dealt with, I omitted the nasal syringing on the theory that an antiseptic strong enough to kill the meningococcus will probably have a similar effect on the cells of the nasal mucosa, whereas one strong enough only to inhibit their growth will so injure the nasal mucosa as to render it even more unable to resist the attacks of the organism. The result of these measures, as of those of Dr. Nicholls, was absolutely: successful, not a single case occurring amongst the natives in the vicinity until six months afterwards, when the second epidemic occurred amongst natives lately imported from a totally different source.

\section{Second Series.}

This, epidemic, as above mentioned, occurred amongst natives employed as military porters, who had been for a month in Mombasa, and amongst whom, while in Mombasa, a few sporadic cases had occurred.

Case 1B.-Aged about 14. Physique and general condition pror. Onset almost insidious, with mild headache, very slight stiff-neck, and slight pains in the limbs. These increased until, on the third day, the headache was very severe and the head retraction excessive. On the fifth day semiconsciousness supervened, with, at times, delirium, in which the patient was very restless, and, on one occasion, eluded his watchers and walked 400 yards before he collapsed. This condition continued for some eight days, during which wasting became excessive. Recovery com. menced about the twelfth day, proceeded uneventfully, and was complete in about five weeks from the onset.

There followed five cases of no special interest, four of which died. These five cases showed a tendency for the disease to assume a more virulent type, as eridenced by the suddenness of onset, severity of general symptoms, excessive head retraction, shortened time before the onset of unconsciousness, and the rapidity of the occurrence of death. None of the cases that died had any treatment other than symptomatic. The one that recovered was treated with intramuscular injections of soamin, gr. 5, on alternate days, but only in the later stages of the disease when convalescence was well established-i.e., during the later stages of the epidemic, when I made the exhibition of soamin a routine measure.

CASE 2B.-Aged about 25. Physique and general condition exceptionally good. History of syphilis probable, but not very clear. Taken ill at 6 P.M. with severe headache, and pain in the back of the neck and back. The obtainable history is not very clear, except that he was obviously very ill quite soon after the onset. About 2 A.M. unconscicusness supervened, and continued without remission until death. When I first saw him at 9.30 the next morning he was deeply unconscious, with rapid stertorous breathing, and in a condition of absolute flaccidity, and presenting no sign of meningitis excepting the unconsciousness. The general aspect of the case was almost exactly like that of a severe cerebral hæmorrhage. The pupils were of medium size, reacting to light. No strabismus. There was absolutely no resistance to any passive movements of any kind. Fæces had been passed, the bladder was distended, necessitating the use of a catheter. Though I was naturally on the lookout for meningitis, I could not correlate this case with any known manifestations of that disease, and made a tentative diagnosis of cerebral hæmorrhage. The patient died at 11 A.M., 17 hours after the onset of symptoms. At the postmortem examination I found thick, creamy, yellow pus 
involving the whole brain and spinal cord, especially abundant at the vertex. The ventricles were filled with turbid fluid, and the ependyma slightly injected.

The 10 or 12 following cases were of the ordinary acute or fulminating type, and betrayed a gradual though distinct tendency for the later cases to be of more virulent nature, both as regards the suddenness of onset, shortness of time before unconsciousness supervened, and rapidity of death. The average history would be sudden collapse of the patient while at his work, complaint of pain in the back of the neck and across the shoulders, and headache of varying intensity. In one or two cases the headache seemed to be almost absent, pain in the head not being complained of until quite late in the disease. In the earlier cases unconsciousness usually came on in the third or fourth day, and death in five to seven days, and in the later ones unconsciousness in from six to 36 hours, and death on the second to the fifth day. Head retraction, Kernig's sign, and general rigidity were present in all these cases; the abdominal and epigastric reflexes were always absent. No cases showed any material change in the tendon reflexes.

CASE 3B.-A case of the ordinary rapid type with unconsciousness on the third day and death on the fifth day. On the third day enormous quantities-several ounces-of thick yellow pus were discharged from the nose. In this pus I demonstrated the presence of intracellular diplococci.

CASE 4B.-A case of the rapid type with death on the third day. Unconsciousness supervened only about 10 hours before death. On the second day diarrhœa commenced, at first with the passage of fæcal stools; afterwards no fæcal matter was passed, but large quantities of mucus mixed with yellow pus. Unfortunately, I was unable to examine this pus microscopically.

CASE 5B.-Aged 22 or 23. Physique and general condition good. Sudden collapse while at work at 12 o'clock midday. Within half an hour the patient was unconscious, and died at 2 P.M. The post-mortem examination showed a slight excess of cerebro-spinal fluid, containing pus cells and intracellular diplococci.

At this stage, three weeks after the outbreak of the epidemic, the general run of cases showed a tendency to diminution of virulence according to the standards above set forth, while coma lasted a shorter time, and death became less inevitable.

CASE 6B.-The patient was of good physique, but the general condition was unsatisfactory. He came as an ordinary out-patient, complaining of headache. I found stiffness of the neck and a very doubtful Kernig's sign, and gave him a prophylactic dose of soamin, gr. 5. The next day he complained of pains in the arms and legs, and there was slight head retraction, and an undoubtedly positive Kernig's sign, together with distinct general muscular rigidity of the limbs. For three weeks the neuritic pains in the limbs continued, and he complained of girdle pains involving the trunk roughly from the dorsal roots 9 to 12 , and I was able to demonstrate a band of hyperæsthesia involving the skin area of the same dorsal nerve roots. I could not find any anæsthesia. Weakness of the legs increased and eventually became excessive. The knee and ankle jerks were very weak, but could always be obtained with difficulty, but there seemed no doubt that the weakness of the legs, though largely due to the general condition, was to be partly accounted for by a definite myelitis involving the anterior cornua of grey matter of the lumbar region, or neuritis of the anterior nerve roots. Wasting of the muscles of the legs was very excessive.

At no time did this case show any signs referable to cerebral meningeal involvement, except for the very slight headache and almost negligible retraction of the head. Recovery was gradual but complete, the patient complaining of pains of a rheumatic type in the limbs for a fortnight or three weeks after the cessation of all active disease.
CASE 7B.-Almost exactly similar to Case 6B, except that the first symptom was neuritic pains in the limbs. The arms in this case were more involved than the legs, and there was indefinite hyperæsthesia over the chest. In this case there was rather more head retraction than in the last case, and a distressing feature was a very severe herpes labialis involving. the upper and lower lips, and spreading outwards on either side of the corners of the mouth.

CASE 8B. - A case of mild type and slow onset. On the fourth day the temperature rose to $107^{\circ} \mathrm{F}$., and I found signs of a slight broncho-pneumonic condition at the left base. The hyperpyrexia continued for three days with a temperature of from $105^{\circ}$ to $107^{\circ}$, and the case ended in complete recovery.

CASE 9B. - This patient, aged about 17, was of very poor physique and general condition, and had been attending as out-patient for a month with chronic headache and a temperature of from $99^{\circ}$ to $100^{\circ}$ every day, to account for which I found nothing on physical examination. He eventually developed a Kernig's sign and head retraction. Eventual complete recovery.

I adopted the same prophylactic measures in this epidemic as were so successful in checking the first. On two occasions the bathing of the 800 natives implicated in cyllin 1 in 400, and their clothes, bedding, \&c., in cyllin 1 in 200 , was carried out. The camp in which they lived was twice moved, the corrugated iron, of which the huts were made, being at the same time exposed to the sun for two days. Isolation of contacts was, of course, carried out and a strict isolation of cases enforced. The hut in which any case had occurred was broken down and the iron composing it exposed to the sun for two days and all the huts had their roofs removed every day, so that the vertical sun could get at the interior. As a last despairing measure the camp was split into two separate halves, and each half into two sections, in the hope that one section might be declared free from the disease, but no good resulted, and the disease only died out when all the natives were returned to their own homes in a part of the country where cerebro. spinal meningitis is endemic and not epidemic.

The treatment adopted was in the main sym. ptomatic, but in the later stages of the epidemic intramuscular injection of soamin, gr. 5, on alternate days was carried out on every case, both in the case of those in the acute stage and of those convalescent from the acute stage in the earlier stages of the epidemic. As regards these injections the syringe and needle were carried in a small tin filled with cotton-wool soaked with methylated spirit. The soamin was made up in a solution of gr. 1 in $m 5$ of filtered water, sterilised by boiling, and kept in a small glass-stoppered bottle holding. 16 doses. For use the syringe was removed from the spirit-soaked wool (a small piece of which was used to cleanse the patient's buttocks), the needle. inserted into the bottle and the required dose drawn up into the syringe, and injected into the buttocks of the patient. If, as was almost invariably the case, another injection had immediately to be given, the process was repeated without further sterilisation, and though I gave upwards of 300 injections in this way, in no instance did any untoward symptoms occur.

Persons attacked.-It will be noticed in the cases which I have detailed above that in patients of strong physique and good general condition the onset was rapid and sudden, the attack severe, and death the rule, whereas the milder cases invariably occurred in the poorer specimens. The two most virulent cases that came under my notice were Cases $2 \mathrm{~B}$ and $5 \mathrm{R}$, and these were both natives of exceptional physique and general condition: 
whereas the mildest case and the one showing the most insidious onset was in a patient of exceptionally poor physique and in a condition of very poor health for one month before he developed the disease. Doubtless, however, I failed to diagnose many still milder cases. This is an extraordinary and, I think, inexplicable feature of my cases, and one that held good, almost without reservation, throughout the two epidemics.

Conditions of bronchial catarrh were very common amongst the natives in whom the second epidemic occurred, amounting certainly to 25 per cent. of the whole number, but I have not been able, on looking over my notes, to correlate any special terdency for those so affected to be attacked by meningitis.

Incubation period.-I obtained no evidence to enable me to make any statement as regards this. Three weeks elapsed after the porters were brought from Mombasa to the highlands before the first case occurred, but his only serves to prove that someone must have carried the virus about with him for that period without showing any symptoms.

Prodromal symptoms.-I was unable to notice any constant prodromal symptoms. The disease usually attacked perfectly healthy individuals without any warning. In one case there had been low fever and headache from an unknown cause for nearly a month before meningitis became obvious, but this had probably nothing to do with the disease.

\section{The Onset and Acute Stages of the Disease.}

These may be divided into five general types or degrees of acuteness :- (a) Fulminating type, (1) exhibiting the ordinary symptoms of rigidity, \&c., and (2) accompanied by coma so deep as to give rise to complete flaccidity; (b) acute type; (c) the common type, less acute than $(b) ;(d)$ subacute type; (e) those cases in which symptoms of cerebro-spinal meningitis are practically or entirely absent; and (f) spinal type. These must not be taken as pathological, or even clinical entities, but merely as an attempt at classification and subdivision of the disease into the forms in which it is usually seen. For the purposes of description cases complicated by infection by the meningococcus of other organs than the meninges may be placed in a separate category as under $(g)$ combined infection, (1) with rhinitis, (2) with conjunctivitis, (3) ? with enteritis.

(a) Fulminating type.-1. A very common form, of which Cases $3 \mathrm{~A}$ and $5 \mathrm{~B}$ are examples. The onset is very sudden, and in a few minutes the patient is completely collapsed. Unconsciousness comes on within an hour or two, but is never so complete that the general muscular rigidity is lost, though the irritability usually seen in meningitis is com. monly absent. Death is almost invariable. 2. A rare form of which I have only seen one exampleCase 2B. Diagnosis of this form is probably impossible except by the examination of the cerebrospinal fluid, as the clinical condition presents no resemblance to the commonly accepted picture of meningitis.

(b) The ordinary extremely acute form, in which the onset is sudden, with headache, pain in the back of the neck, and very frequently with pain across the shoulders, with or without the headache and pain in the neck. The patient is very ill within a few hours of the first symptoms, and coma supervenes in from 24 to 48 hours. The ordinary signs and symptoms of meningitis are always present, headache being always acute, head retraction often excessive, Kernig's sign strongly positive, and irritability continues throughout the coma.

(c) The commonest form is something between Type $(b)$ and Type $(d)$. The mode of onset is variable, ranging from practically the same thing as in Type $(b)$, sometimes accompanied by rigor, to insidious headache, gradually intensifying, with pain radiating down the neck and across the shoulders. In other cases rheumatic pains in the limbs, and usually across the shoulders, are the first complaint. If the patient is examined in the earliest stages it will generally be found that there is resistance to anteflexion of the head, and if the head is forcibly rotated so that the head looks towards one or other shoulder, pain is complained of. A forcible depression, and at the same time forward movement of the shoulders, causes discomfort. Withiu 24 hours the nature of the case has usually become obvious by reason of the marked stiffness of the neck or even obvious head retraction, and the presence, to a greater or less degree, of spasm of the ham-strings, giving rise to Kernig's sign. This type of case usually becomes semi-unconscious, with continuance of excessive irritability and dislike to being disturbed through. out the acute stages of the disease, and in five to seven days is usually on the way to recovery. Sometimes in this type of case coma deepens, is protracted, and the patient dies from exhaustion or toxic absorption.

(d) Subacute type.-In this form onset is very insidious, usually with headache, and often with pains of a rheumatic type in the limbs, back of the neck, and across the shoulders. These may continue for several days before the persistence and increasing severity of the headache and occurrence of stiffness of the neck or head retraction give rise to suspicion of the true nature of the disease. The duration of the active stage is from seven to ten days, and complete recovery is the rule. This form is exemplified by Cases $6 \mathrm{~B}$ and $9 \mathrm{~B}$.

(e) Cases unaccompanied by the ordinarysymptoms of meningitis. - These are cases of a very mild type which range from Type $(d)$ to those in which there are no symptoms, and the diagnosis rests on the demonstration of the meningococcus in the nasal mucus. In these cases at the extreme end of a long series of types of decreasing virulence, there is probably very slight or no infection of the meninges, the sole lesion being a meningococcal infection of the naso-pharynx. I probably encountered many such cases, but, owing to circumstances especially inauspicious for investigation, completely failed to recognise them.

(f) Cases in uhich spinal symptoms predominate. - These cases are obviously due to the predominating implication of the spinal meninges, whilst the cerebral meninges are comparatively little affected. Possibly there is a definite infective myelitis of the cord and neuritis of the spinal nerve roots, or in other cases these may be of toxic origin only. Cases 6B and 7B are examples of this type, different regions of the cord being affected.

(g) Cases in which there is meningococcal infec. tion other than that of the meninges.-(1) Rhinitis and naso-pharyngitis.-This is probably of universal occurrence, to a greater or less degree, in every case of cerebro-spinal meningitis, and is probably the initial lesion. In certain instances, of which Cases $2 \mathrm{~A}$ and $3 \mathrm{~B}$ are examples, it becomes a marked feature of the case by reason of the excessive amount of pus discharged therefrom. 
(2) Conjunctivitis.-This is probably caused merely through the accidental inoculation of the meningococcus on to the conjunctiva, or possibly it is an ascending. infection from the nose via the lacrymal duct, and is of no special interest. Examples are quoted in Cases $1 \mathrm{~A}$ and $2 \mathrm{~A}$.

(3) Enteritis.-In the absence of any positive evidence on this I can say nothing. The point is of importance in connexion with prophylaxis as regards the treatment of fæeces, not so much in England, where the method of disposal of sewage prevents the desiccation and pulverisation of fæces, as in places where the earth system is the rule.

\section{General Symptoms and Signs.}

We have, therefore, in cerebro-spinal meningitis a disease varying widely in type, acuteness and severity. At one end of the scale it is a disease of such exceptional severity and acuteness that it can cause death in so short a period as two hours (vide Case 5B), and at the other end occur cases with possibly no symptoms, and in which the existence of a definite meningeal infection is improbable, though there is certainly a meningococcal nasopharyn gitis.

I have already discussed, incidental to the description of cases, and analysis of the types of the disease, the common signs and symptoms of the disease. It remains, therefore, only to touch on one or two other points of interest.

Temperature.--In the average case this rises rapidly with the onset of symptoms to anything between $100^{\circ}$ and $103^{\circ}$, and thereafter is very irregular until all active disease has ceased. In Case 6B, which I saw very early, almost before the signs of meningitis had developed, the temperature had already reached $100^{\circ} 2^{\circ}$. In one case (8B) the temperature rose to $107^{\circ}$ and remained near that height for three days, but this case was not wholly uncomplicated, there being a broncho-pneumonic condition of the lungs at the same time.

The pulse.-This shows nothing characteristic. I was quite unable to verify the popular supposition that the pulse is comparatively slow in meningitis, as in every case the pulse-rate was in keeping with the height of temperature then prevailing.

Subcuticular hamorrhages.-These were never observed, possibly owing, in some measure, to the black skin of the patients.

Ocular palsies.-These are said to be very common in meningitis. I, however, never saw them in any case of this series.

Optic neuritis.-I was debarred by general circumstances and the lack of a suitable lamp from making a routine examination of the fundi oculorum. (Not that $I$ believe that it would be possible under any circumstances with the average raw native.) In no case during convalescence or on recovery was there any complaint of defective sight.

Treatment.

Dr. J. O. Shircore, of the East African Medical Service, has written a very able article praising the effect of intramuscular injections of soamin in meningitis. $\mathrm{He}$ claims that the drug is excreted into the cerebro-spinal fluid and there has a deterrent effect upon the growth of the organism, and he gives results of the examination of the cerebro-spinal fluid of cases before and after the use of the drug, from which he claims that its use caused degeneration of the diplococci. That may be so, but in the 35 odd cases that I have used the drug I have failed to notice any benefit from its use: Nor could I observe any difference between the general course of the disease in those cases in which it was used and those in which it was not used. Ordinary general treatment on symptomatic lines was adopted in all my cases.

Lumbar puncture $\mathbf{I}$ could not employ, for reasons explained above, though from previous experience of its use in cases. of post-basic meningitis I very much doubt its efficiency as a therapeutic measure, saving insomuch as its good effect on headache and other pressure symptoms is undoubted.

\section{Morbid Anatomy.}

In all cases I found evidence of pyogenic in. fection of the meninges of the brain and spinal cord, and in all such as microscopic examination of the cerebro-spinal fluid was carried out the meningococcus was demonstrated. The fluid varies from the merest possible turbidity to thick, creamy, yellow pus. In one or two cases there was a preponderance of the pus at the base of the brain, but in the great majority it ascended well on to the vertex and descended into the greater fissures of the brain.

Neither of the cases that showed a preponderance of spinal symptoms came to necropsy, so that the question of the existence of a definite infective, or only toxic, myelitis and neuritis must remain unsolved.

The existence of thick pus in Case 2B, which died 17 hours after the onset of symptoms, is a little difficult to explain on pathological lines.

Cerebro-spinal Meningitis and Post-basic Meningitis, and the Development and Cessation of Epidemics.

The difference between these two diseases is an etiological rather than a clinical one, insomuch as the first is the epidemic form of the second. They are both caused by organisms morphologically identical, though differing in the physiological character of virulence.

Several sporadic cases of meningitis occurred amongst the same group of natives as supplied the second epidemic while at Mombasa, and since they left that place sereral further sporadic cases hare occurred amongst others of their number who remained at the coast. When brought into the cooler climate of the highlands nearly three weeks elapsed before the first case occurred, the next case was two days after, another followed the next day, and thereafter cases occurred at the rate of about two a day for three weeks. On some days as many as four new cases occurred, on others only one. After the three weeks the rate of incidence gradually declined, until during the last week before the whole group of natives were returned to Uganda, and out of my care-i.e., the sixth week of the epidemic-only two fresh cases occurred.

Parallel with the rise and fall of case incidence ran the virulence and acuteness of the attacks. This was so well marked that I have no doubt that if it were plotted out there would be a definite and nearly regular curve showing the rise and fall of virulence of the virus.

I have no definite information on the point, but had the epidemic continued after their return to their homes where the disease is endemic I should certainly have heard of it, and so the two ends of the curve would indicate the point where sporadic post-basic meningitis merges into epidemic cerebro-spinal fever.

Magadi, British East Africa. 